\title{
Cut Price Adolescent Units that meet All Needs and None?
}

Peter Wells, Consultant Adolescent Psychiatrist, Macclesfield Health Authority, Young People's Unit, Macclesfield

As a junior doctor, I worked on an adolescent unit attached to a large mental hospital. Since it provided a base for a regional service, it struggled to cope with referrals of all kinds. The in-patient population consisted of youngsters of both sexes exhibiting a wide variety of disorders ranging from psychosis, anorexia and brain syndromes to emotional and conduct disorders. The turnover was low: about 18 admissions per year to the 18 beds. This resulted in a lengthy waiting list which afforded the unit some protection: seriously acting out and other very pressing problems that could not wait often had to go elsewhere.

Nevertheless, although the waiting list succeeded in excluding some of the more seriously disturbed, the effect of mixing mad adolescents with those who were not psychotic, particularly those exhibiting delinquent behaviour, appeared to me to diminish the effectiveness of the unit in a number of ways.

Firstly, the team were uncertain how to respond to destructive behaviour - should they be given more medication or a bill? To the adolescent with a behaviour disorder, medication implies that he is ill, and cannot be held responsible for his behaviour; it also feeds his panic that his inability to manage his tumultous feelings is, after all, crazy. (I remember on one occasion having to intervene to prevent three or four young people attacking a schizophrenic patient on the same unit in an attempt to drive her and her mad behaviour out. She eventually had to be moved to an adult ward, for her own safety, where to everyone's surprise she rapidly improved).

Secondly, the staff were confused over the aims and goals of treatment, and anxious about control. Life on an adolescent unit is difficult and exhausting enough without the added burden of lack of clarity and inconsistency. It seemed to me, struggling with the team to cope with so many diverse needs, that our attempts to provide an answer for almost everything was a recipe for chaos.

\section{Getting the right mix}

If, as seems generally accepted, the adolescent psychiatrist cannot offer the universal remedy for all adolescent disorders, which of them can he treat? One obvious choice for doctors highly trained in the application of diagnostic skills is those categories for which such skills are most useful. Studies of referrals to adolescent services or of the incidence of adolescent disorders in the community, however, demonstrate that the 'diagnostic' group is a very small one. The rest of the disturbed population consists of broad categories: emotional, conduct and mixed emotional and conduct disorders, which account for between $80 \%$ and $90 \%$. Referrals to a regional adolescent service reflect these proportions.
This poses a dilemma. If mixing psychotics and other 'ill' adolescents with youngsters exhibiting emotional and conduct disorders does not work, should they not be treated separately? The pressure by referrers to treat the majority consumer group is considerable, which suggests that alternative services do not have adequate resources to manage a large number of them.

Although the published results of the outcome of treatment on adolescent units of emotional disorders is reasonably satisfactory, that of conduct disorders is disappointing: usually not more than half show improvement.

It is perhaps not surprising that many adolescent psychiatrists place disproportionate emphasis on the very small 'diagnostic' group of disorders when selecting for treatment, although most also offer to treat some emotional disorders and a few of the more socialised conduct disorders. Others regard conduct disorders as largely a matter for the penal system. As a result in-patient populations tend to be skewed, and are not a rejesentative sample of disorders at large.

Around $80 \%$ of adolescent offenders are reconvicted within two years of leaving youth custody or detention centres. Although the populations are not strictly comparable, treatment of many conduct disorders does achieve more satisfactory results than this. In an attempt to deal with this particularly daunting but very large group, the Young People's Unit in Macclesfield does not admit psychotic youngsters, who accordingly are treated as out-patients or elsewhere. Our policy of treating the majority consumer group at the cost of excluding a very small minority (around $1 \frac{1}{2} \%$ of referrals), which seemed an appropriate priority in view of the demands, has nevertheless invited critical comments; expensive units which operate an overt selection policy tend to attract elitist or other perjorative labels. They are difficult to justify however unless they admit only those for whom the treatment is likely to prove effective. Followup studies suggest that the treatment of psychotic illness is even less effective than that of many conduct disorders.

There also seems to be a fairly universal opinion that psychotic adolescents should not be treated on adult wards. It stems partly from the supposed risk; however, the harm from exposing a vulnerable adolescent to a seriously disturbed or delinquent peer group can at times be very much greater. The risk of adolescents disturbing adult patients or the equanimity of adult ward staff can perhaps be justified in certain circumstances.

Support for a more selective approach is given in a recent consumer survey in which the views were canvassed of discharged adolescents and their parents on the treatment given them on what they described as a 'general purpose adolescent unit'. Patients and relatives regarded as harmful 
the location of the unit in a psychiatric hospital, with its implications of mental illness. One of the conclusions in the paper is that a more selective approach should be 'dependent on a regional plan to establish units with different styles of regime suited to the treatment of different disorders.'

\section{An identikit service?}

The fantasy that adolescent units should be capable of responding to almost all needs is not quite avoided by those expressing alternative views. In a critique of the current state of adolescent psychiatry in Britain, Parry-Jones ${ }^{2}$ concludes 'it seems that greater uniformity in the admission policy of in-patient units, providing for a wider range of disorders, would make better use of resources'. This view is taken further in the recent Health Advisory Service Report $(1986)^{3}$ on adolescent services, Bridges over Troubled Waters', which states, 'psychiatric units for adolescents must each offer a range of methods of treatment and move towards more uniform admission policies', and, 'psychiatrists must ensure that disturbed adolescents who are suffering from mental handicap, sensory handicap, acquired brain damage, chronic physical illness and autism are not excluded'. The report contains no suggestion that a comprehensive service offering an appropriate response to these very diverse needs needs to be provided with separate units. The emphasis is on a more stereotyped rather than a versatile response.

Proposals have recently been made to condense two of three separate units for treating disturbed young people at the Maudsley to save money (The Times, 28 April 1986). It is a small step in administrative logic to house indiscriminate admissions in one, rather than two buildings, if indeed the profession is openly saying that a selective approach is no longer justifiable.

The report not only requires the adolescent psychiatrist to exclude few, if any, from his all-embracing treatment, but goes on to say, 'psychiatrists providing services for adolescents have a primary responsibility for all those suffering from identifiable psychiatric disorders'. The provision of comprehensive services has hitherto been the responsibility of Regional Health Authorities advised by the specialists in the field. In the Mersey Region, for example, a recent working party recommendation that a special unit be built for psychotic and other sick adolescents, who cannot be treated adequately on existing units, has been accepted by the Regional Health Authority. The Health Advisory Service proposes that adolescent psychiatrists be saddled with the primary responsibility for offering a service, without also making a case for a range of facilities and resources to meet diverse needs.

Recommendations of this kind in the Health Advisory Service Report are too vague. Their over-inclusiveness permits an interpretation which can be used politically to close units who try to be effective by selection, or in the case of the Maudsley, to propose housing all referrals in one rather than two units. This makes me and other colleagues anxious: in the last two decades we have been moving away in this country from a situation that can only be stigmatized as the warehousing of disturbed children in large community homes. What may seem politically expedient on the grounds of economy may not allow for good practice. It is to be hoped that the working party recently set up by the College to examine the 112 Health Advisory Service recommendations for adolescent psychiatric services will bring clarity and greater precision in their interpretation of what this rather politically naive document intends, and whether, if implemented with no financial backing, the effect on the service will be to further, or to diminish the opportunities for good practice.

\section{ReFERENCES}

1 PYNe, N., Morrison, R. \& Ainsworth, P. (1986) A consumer survey of an adolescent unit. Journal of Adolescence, 9, 63-72.

${ }^{2}$ PARRY-JONES, W. (1984) Adolescent psychiatry in Britain: a personal view of its development and present position. Bulletin of the Royal College of Psychiatrists, 8, 230-233.

${ }^{3}$ NHS Health Advisory Service (1986) Report on Services for Disturbed Adolescents. Bridges over Troubled Waters. London: HMSO.

A full list of references is available from the author on request.

\section{The Lambo Foundation-An Appeal}

The poor opportunities for advancement in academic medicine and the cuts in many Governments' grants to medical schools in tropical Africa have meant that the standards of medical education are seriously threatened by a lack of doctors with qualifications in the specialties who can run the teaching programmes.

The Lambo Foundation for the Advancement of Biomedical and Biobehavioural Sciences aims to improve medical education, medical research, and health care in Africa, particularly in Nigeria. The Foundation was established in 1982 by Professor and Mrs T. A. Lambo. It has awarded five fellowships in medical and health development and has set up five centres in Africa for the study of endocrinology, a clinical centre, and an acupuncture centre (in Lagos). The Foundation is now appealing for secondhand equipment and books. Medical books and back copies of all medical journals are urgently needed. ECG and ECT machines, ultrasound diagnostic apparatus, and other basic equipment will also be welcome. The Foundation will distribute books and equipment and will pay for postage and transportation costs to Geneva. Correspondence and donations may be addressed to Professor T. A. Lambo, $27 \mathrm{ch}$. des Chataigniers, 1292 Chambésy, Geneva, Switzerland. 